Pak. j. sci. ind. res. Ser. A: phys. sci. 201659 (1) 1-10

\title{
Preparation, Characterisation and Photocatalytic Activity of La-doped ZnO Nanopowders Synthesised using Auto-combustion
}

\author{
Mukhtar Ahmad ${ }^{\text {ab* }}$, Eijaz Ahmed ${ }^{\mathrm{a}}$, Muhammad Ikram ${ }^{\mathrm{a}}$, Zhanglian Hong ${ }^{\mathrm{b}}$, Abdul Hafeez ${ }^{\mathrm{c}}$, \\ Khalid Nadeem Riaz ${ }^{\mathrm{d}}$, Fezza Zafar ${ }^{\mathrm{a}}$, Niaz Ahmed Niaz ${ }^{\mathrm{a}}$ and Waqar Ahmed ${ }^{\text {ef }}$ \\ ${ }^{a}$ Department of Physics, Bahauddin Zakariya University, Multan 60800, Pakistan \\ ${ }^{\mathrm{b}}$ State Key Laboratory of Silicon Materials, Department of Materials Science \& Engineering, \\ Zhejiang University, Hangzhou 310027, China \\ 'Science and Technology Division, University of Education, Lahore, Pakistan \\ ${ }^{\mathrm{d} D e p a r t m e n t ~ o f ~ P h y s i c s, ~ U n i v e r s i t y ~ o f ~ G u j r a t, ~ G u j r a t ~ 50700, ~ P a k i s t a n ~}$ \\ ${ }^{\mathrm{e}}$ Institute of Nanotechnology and Bioengineering, University of Central Lancashire, School of Medicine, \\ Preston PR1 2HE, United Kingdom \\ fDentistry and School of Pharmacy, Preston PR1 2HE, United Kingdom
}

(received August 18, 2014; revised August 9, 2015; accepted August 18, 2015)

\begin{abstract}
Nanocrystalline nanoparticles of pristine $\mathrm{ZnO}$ and La-doped $\mathrm{ZnO}$ have been synthesised using a combustion method using various concentrations of lanthanum dopant followed by calcination for $3 \mathrm{~h}$ at $700{ }^{\circ} \mathrm{C}$. The crystalline structure, chemical composition and optical characteristics have been characterised using X-ray diffraction (XRD), scanning electron spectroscopy (SEM) attached with energy dispersive X-ray (EDX) spectroscopy, Brunauer Emmett Teller (BET), UV-vis. spectroscopy and photoluminescence (PL) spectroscopy. Absorption spectra showed that the absorbance increased with La-doping and the blue shift observed was due to an increase in the band gap from 3.24 to $3.27 \mathrm{eV}$. The photocatalytic activities of the samples prepared were evaluated using the photocatalytic degradation of methyl orange (MO) under irradiation by sunlight. The textile mill effluents containing organic matter were also irradiated with sunlight inducing photocatalysis and the chemical oxygen demand (COD) of the treated effluent were investigated. The results showed that the $\mathrm{ZnO}$ photocatalyst doped with 1.0 at.\% lanthanum exhibited four times enhancement in the photocatalytic activity compared to pure $\mathrm{ZnO}$.
\end{abstract}

Keywords: $\mathrm{ZnO}$, combustion, XRD, photocatalysis, methyl orange, La-doped $\mathrm{ZnO}$

\section{Introduction}

Fabrication and characterisation of semiconducting nanostructured materials have received considerable attention over the last few years due to increasing influence on our everyday life (Suwanboon and Amornpitoksuk, 2011; Wang and Herron, 1991). Zinc oxide $(\mathrm{ZnO})$ has attracted interest due to its photocatalytic ability useful for the degradation of environmental pollutants and is attractive alternative to $\mathrm{TiO}_{2}$ as a photoactive catalyst (Kaneva et al., 2011; Anandan et al., 2007). $\mathrm{ZnO}$ has exhibited superior performance with lower cost compared to $\mathrm{TiO}_{2}$ in degrading organic dyes in acidic and basic media. It has a hexagonal wurtzite structure with an $n$-type conductivity (Reddy et al., 2011; Chen et al., 1998). The structural, optical, electrical and physical properties of $\mathrm{ZnO}$ nanoparticles and the effects of doping on these properties have been studied earlier by several researchers (Ahmad et al., 2013; Shinde et al., 2006; Ismail et al., 2001). Dramatic *Author for correspondence; E-mail: mzkhm73@gmail.com changes in the electrical and optical properties of $\mathrm{ZnO}$ and unique properties due to doping have been observed by Bouderbala et al. (2008). Due to its useful properties, $\mathrm{ZnO}$ has been used in photocatalytic applications (Xiao et al., 2015; Zhou et al., 2009). ZnO is an ideal catalyst in photocatalysis since it is nontoxic with holes of strong oxidising power and being inexpensive (Peng et al., 2007). When $\mathrm{ZnO}$ nanoparticle is illuminated with a light of appropriate wavelength, the valence band potential is positive enough to generate hydroxyl radicals at the surface, and the conduction band potential is negative enough to reduce molecular $\mathrm{O}_{2}$. The hydroxyl radical is a powerful oxidising agent and can attack organic pollutants present at or near the surface of the $\mathrm{ZnO}$ to degrade it. However, the photocatalytic efficiency at the present stage is still very low, which is mainly caused by the fast recombination of photogenerated electron-hole pairs during photocatalysis. Thus, further improving the photocatalytic efficiency is still a major challenge in the research field of photocatalysis until 
now. Therefore, for enhancing photocatalytic activity of $\mathrm{ZnO}$, doping of metal or nonmetal ions is a useful technique (Abed et al., 2015; Elangoran et al., 2015). Metal doping induces localized states between the valence band and the conduction band. These mid-gap states could trap temporarily the photogenerated electronhole pairs, thus suppress the recombination of charge carriers (Wan et al., 2015; Zhao et al., 2015). Recent research has been focused on the doping of $\mathrm{ZnO}$ by lanthanide ions with $4 \mathrm{f}$ electron configuration. Lanthanide ions can form complexes with various Lewis bases including organic acids, amines, aldehydes, alcohols, and thiols by the interaction of the functional groups with their f-orbital (Ahmad et al., 2015). Thus, doping lanthanide ions into a $\mathrm{ZnO}$ matrix could provide a means to concentrate organic pollutants on the semiconductor surface and therefore, can improve the separation efficiency of photo-induced electron-hole pairs of $\mathrm{ZnO}$ to enhance the photoreactivity (Ahmad et al., 2015; Ciciliati et al., 2015).

In this study, pure $\mathrm{ZnO}$ and La-doped $\mathrm{ZnO}$ using the auto-combustion technique has been synthesised producing highly pure nanocrystalline powders with large surface area at relatively low temperatures (Hwang and $\mathrm{Wu}, 2004)$. Variations in the properties of $\mathrm{ZnO}$ powders were studied as a function of the lanthanum dopant concentrations.

\section{Materials and Methods}

Synthesis of undoped and La-doped $\mathrm{ZnO}$ nanopowders. Pure and La-doped $\mathrm{ZnO}$ nanopowders were synthesised using the combustion technique. Zinc nitrate $\left(\mathrm{Zn}\left(\mathrm{NO}_{3}\right)_{2} \cdot 6 \mathrm{H}_{2} \mathrm{O}\right)$ and glycine $\left(\mathrm{NH}_{2} \mathrm{CH}_{2} \mathrm{COOH}\right)$ were used as starting reagents. The zinc nitrate served as a source of zinc and as an oxidising agent whereas glycine acted as a fuel (Ahmad et al., 2013).

Precursor formation. For pure $\mathrm{ZnO}$, homogeneous mixture of glycine and zinc nitrate was obtained by mixing them together in the optimised molar ratio (Ahmad et al., 2012a) through magnetic stirring. This resulted in the formation of transparent slurry by absorbing moisture from air due to the hygroscopic nature of zinc nitrate. The slurry was then dehydrated at $130{ }^{\circ} \mathrm{C}$ to obtain precursor using a hot plate.

Auto-ignition. The precursor was heated at $200{ }^{\circ} \mathrm{C}$ to cause precursor ignition. During combustion the evolution of gases occurred with generation of heat. Heat treatment at $700{ }^{\circ} \mathrm{C}$ was done for $3 \mathrm{~h}$ resulting in the liberation of gases and formation of dry, crystalline white $\mathrm{ZnO}$ powders. For the preparation of La-doped $\mathrm{ZnO}$ samples, lanthanum nitrate $\left[\mathrm{La}\left(\mathrm{NO}_{3}\right)_{3} \cdot 6 \mathrm{H}_{2} \mathrm{O}\right]$ was added to the initial mixture of zinc nitrate and glycine. Rest of the process was similar to that used for pure $\mathrm{ZnO}$. The following chemical reaction occurs during the synthesis of La-doped $\mathrm{ZnO}$ samples:

$\mathrm{Zn}\left(\mathrm{NO}_{3}\right)_{2} \cdot 6 \mathrm{H}_{2} \mathrm{O}+\mathrm{La}\left(\mathrm{NO}_{3}\right)_{3} \cdot 6 \mathrm{H}_{2} \mathrm{O} \stackrel{\text { Glycine }}{\longrightarrow} \mathrm{Zn}_{1-x} \mathrm{~L}_{\mathrm{x}} \mathrm{O}$

+ Gases $\left(\mathrm{CO}_{2}+\mathrm{N}_{2}+\mathrm{H}_{2} \mathrm{O}\right.$ vapours $)$

Characterisation. Powder X-ray diffraction (XRD) patterns of as-synthesised $\mathrm{ZnO}$ and La-doped $\mathrm{ZnO}$ samples were recorded using a Rigaku Dmax-IIIA Xray diffractometer with $\mathrm{Ni}$ filtered $\mathrm{Cu} \mathrm{K} \alpha$ radiation source. The surface morphology, particle size and compositional analysis of photocatalysts were examined using a scanning electron microscope (Hitachi S-4800) with EDX and transmission electron microscope (JEOL JEM 1200EX) and X-ray photoelectron spectroscopy (XPS, VG ESCALAB MARK II) with a monochromatic $\mathrm{Mg} \mathrm{K} \alpha \mathrm{X}$-ray source. Specific surface areas of samples were determined using Brunauer Emmett Teller (BET) surface area analyzer (NOVA 2200e Quantachrome, USA) using nitrogen as a purge gas. UV-vis diffuse reflectance spectra (DRS) were measured in the range of 380-460 nm using a Hitachi U-4100 UV-vis pectrometer. PL emission spectra were recorded using Hitachi F-4500 fluorescence spectrophotometer. The sample excitation was made at $325 \mathrm{~nm}$ at room temperature.

Measurement of photocatalytic activity. Photocatalytic activities of $\mathrm{ZnO}$ and La-doped $\mathrm{ZnO}$ nanopowders were estimated by monitoring the degradation of methyl orange (MO) as a model compound in a self-assembled apparatus under natural sunlight radiation source. In this study, photocatalytic activities under natural sunlight were investigated. The peak at $464 \mathrm{~nm}$ was used to monitor the photocatalytic degradation of MO. For the photocatalytic experiment, $50 \mathrm{mg}$ photocatalysts were suspended in $\mathrm{MO}$ aqueous solution $(50 \mathrm{~mL})$ with a concentration of $20 \mathrm{mg} / \mathrm{L}$ in a beaker. The suspension was magnetically stirred for $30 \mathrm{~min}$ to reach the adsorption/desorption equilibration without light exposure. This was followed by a photocatalytic reaction started by the exposure of the desired light. The temperature of the suspension was kept at about $20^{\circ} \mathrm{C}$ by an external cooling jacket with recycled water. After a setup exposure time, $5 \mathrm{~mL}$ suspension was sampled, centrifuged and the supernatant was taken out for uv- 
vis absorption spectrum measurement. The intensity of the main absorption peak of the MO dye was referred to as the measure of the residual dye concentration.

Analytical method. Total organic carbon (TOC) content was measured after the degradation of model dye in the presence of the photocatalysts under sunlight irradiation (Mukherjee, 2011). After photodegradation, the total organic carbon content of model dye was observed to decrease with time. The decrease of carbon content indicates the degradation of the organic dye into nontoxic decomposed compounds. Moreover, the mineralisation of substrate was measured by chemical oxygen demand (COD) reduction method. Chemical oxygen demand of textile effluent was estimated before and after the photocatalytic treatment with a standard dichromate method, using COD digester. Arsenic effluent was diluted to facilitate light penetration through solution and the initial COD of diluted effluent was $412 \mathrm{mg} / \mathrm{L}$. The amount of catalysts was $50 \mathrm{mg} / 25 \mathrm{~mL}$ and an average intensity of sunlight was $1.20 \times 10^{5}$ lux during the photocatalytic measurements. The percentage photodegradation efficiency $(\eta)$ was calculated from the following expression:

$$
\eta=\left[\frac{\text { CODi }- \text { CODf }}{\text { CODi }}\right] \times 100
$$

Where:

CODi $=$ before treatment

$\mathrm{CODf}=$ after treatment

All the experiments were performed under the same experimental conditions such as sunlight irradiation (between 9 am and $3 \mathrm{pm}$ ), constant temperature, $\mathrm{pH}$ and photocatalyst load etc.

\section{Results and Discussion}

XRD analysis. Figure 1 shows powder X-ray diffraction patterns of pure $\mathrm{ZnO}$ and $\mathrm{La}$-doped $\mathrm{ZnO}$ as a function of lanthanum dopant concentrations. The physical characteristics such as crystallite size and unit cell parameters are presented in Table 1. The strong and sharp peaks existing in the XRD spectra show the presence of wurtzite structure of $\mathrm{ZnO}$. The strong peaks are located at an angle $(2 \theta)$ of $31.7^{\circ}, 34.4^{\circ}$ and $36.2^{\circ}$

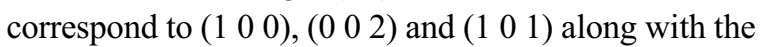
other peaks which are found at the angles of $47.5^{\circ}$, $56.6^{\circ}, 62.9^{\circ}, 66.4^{\circ}, 67.9^{\circ}, 69.2^{\circ}, 72.7^{\circ}$ and $77.0^{\circ}$

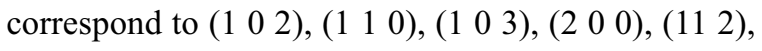
( $\left.\begin{array}{lll}2 & 0 & 1\end{array}\right),\left(\begin{array}{lll}0 & 0 & 4\end{array}\right)$ and $\left(\begin{array}{lll}2 & 0 & 2\end{array}\right)$ planes, which all are found

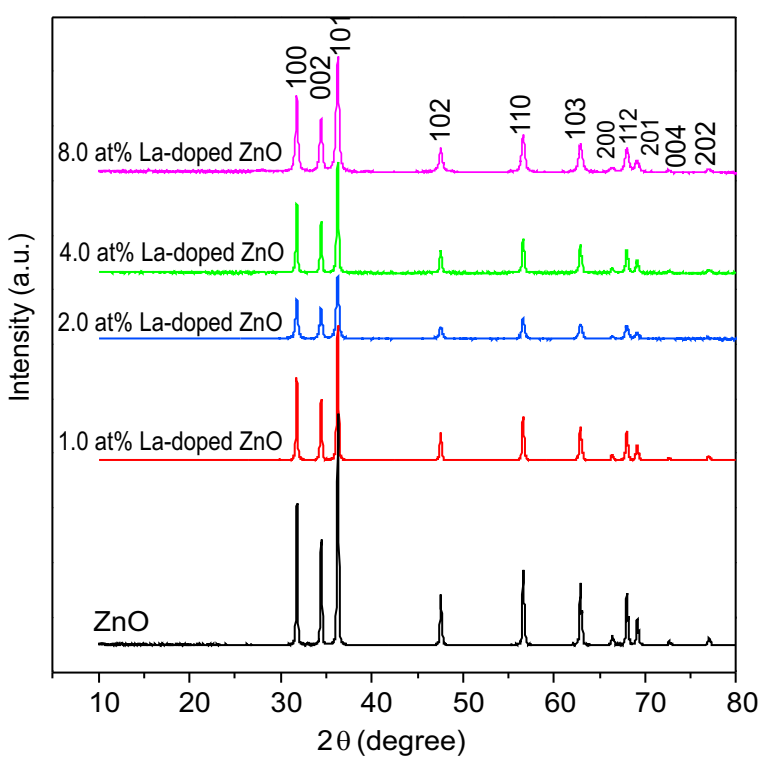

Fig. 1. X-ray diffraction patterns of pure $\mathrm{ZnO}$ and La-doped $\mathrm{ZnO}$ sample

Table 1. Crystallite size and unit cell parameters of pure $\mathrm{ZnO}$ and La-doped $\mathrm{ZnO}$ sample.

\begin{tabular}{lllr}
\hline \hline Photocatalysts & $\begin{array}{l}\text { Crystallite } \\
\text { size }(\mathrm{nm})\end{array}$ & \multicolumn{2}{c}{ Lattice parameters } \\
\cline { 3 - 4 } & 27 & 3.254 & 'a' $(\AA)$ \\
\hline $\begin{array}{l}\text { Pure } \mathrm{ZnO} \\
1.0 \text { at.\% La- }\end{array}$ & 24 & 3.258 & 5.208 \\
$\begin{array}{l}\text { doped } \mathrm{ZnO} \\
\begin{array}{l}2.0 \text { at.\% } \mathrm{La}- \\
\text { doped } \mathrm{ZnO}\end{array}\end{array}$ & 22 & 3.262 & 5.199 \\
$\begin{array}{l}\text { 4.0 at.\% La- } \\
\text { doped } \mathrm{ZnO}\end{array}$ & 23 & 3.263 & 5.195 \\
$\begin{array}{l}\text { 8.0 at.\% La- } \\
\text { doped } \mathrm{ZnO}\end{array}$ & 19 & 3.265 & 5.186 \\
\hline \hline
\end{tabular}

in correspondence to those given in JCPDS 05-0664 and previous studies (Ghouri et al., 2014; Ahmad et al. 2013). The diffraction patterns of La-doped $\mathrm{ZnO}$ were similar to the undoped $\mathrm{ZnO}$ showing that lanthanum doping in $\mathrm{ZnO}$ did not affect its crystal structure. This also indicates that $\mathrm{La}^{3+}$ is uniformly dispersed on $\mathrm{ZnO}$ nanoparticles in the form of small $\mathrm{La}_{2} \mathrm{O}_{3}$ cluster (Anandan et al., 2007). The observed peaks for Ladoped $\mathrm{ZnO}$, however, are wider with the width increasing with increasing La-content. La-doping caused a random variation in diffraction peak intensities. Intensity decreased up to 2.0 at $\%$ La-content and then increased. The change in the intensity and width of the observed diffraction peaks as a function of La-content is attributed to the decrease in the crystallite size (Suwanboon and 
Amornpitoksuk, 2011; Flickyngerova et al., 2008; Anandan et al., 2007), which goes on changing inversely with change in La concentration. Lattice parameters ' $a$ ' and ' $c$ ' were estimated using the formula:

$$
\left[\frac{1}{\mathrm{~d}_{\mathrm{hkl}}}\right]^{2}=\frac{4}{3}\left[\frac{\mathrm{h}^{2}+\mathrm{k}^{2}+\mathrm{hk}}{\mathrm{a}^{2}}\right]+\frac{\mathrm{l}^{2}}{\mathrm{c}^{2}}
$$

Lattice parameters and crystallite size variation as functions of La-content were calculated. The calculated values of lattice parameters 'a' and 'c' are $3.254 \AA$ and $5.208 \AA$ while for 2.0 at.\% La-doped $\mathrm{ZnO}$ are $3.262 \AA$ and $5.199 \AA$, respectively. Lattice parameters increased with increase in La-content which is obvious as ionic radius of $\mathrm{Zn}^{+2}$ is $0.074 \mathrm{~nm}$ and that of $\mathrm{La}^{+3}$ is 0.106 (Suwanboon and Amornpitoksuk, 2011) and lattice parameters should expand if ionic radius of the dopant is greater as compared to $\mathrm{Zn}$ ions (Dole et al., 2011). Average crystallites sizes were estimated using the full width at half maximum (FWHM) of highly intense diffraction peak in Debye-Scherrer's formula (Culity and Stock, 2001).

$$
\mathrm{t}=\frac{0.9 \lambda}{\beta \cos \theta}
$$

Average crystallite size estimated for pure $\mathrm{ZnO}$ to be $27 \mathrm{~nm}$ which decreases up to $19 \mathrm{~nm}$ with increase in La-content. It is interesting to note that the particle size of $\mathrm{La}$ doped $\mathrm{ZnO}$ is smaller as compared with that of the pure $\mathrm{ZnO}$. The decrease in the particle size of Ladoped $\mathrm{ZnO}$ is mainly attributed to the formation of $\mathrm{La}-\mathrm{O}-\mathrm{Zn}$ on the surface of the doped samples, which hinders the growth of crystal grains (Korake et al.,2014; Jia et al., 2009; Anandan et al., 2007).

SEM, EDX and TEM. Figure 2(a-d) displays the surface morphology of pure $\mathrm{ZnO}$ and 2.0 at $\% \mathrm{La}$-doped $\mathrm{ZnO}$ nanopowders. SEM micrographs of pristine $\mathrm{ZnO}$ nanopowders exhibited clusters of tiny particles, whilst 2.0 at $\%$ La-doped $\mathrm{ZnO}$ nanopowders revealed flakes of ultrafine particles with voids or holes. The high porosity in the nanopowders could be attributed to the liberation of large amount of gaseous products such as $\mathrm{H}_{2} \mathrm{O}$ vapours, $\mathrm{CO}_{2}$ and $\mathrm{N}_{2}$ during combustion process (Ahmad et al., 2013b). TEM images in Fig. 2, show that, for undoped $\mathrm{ZnO}$ nanopowders, the particles are spherical and. larger and, while for 2.0 at $\%$ La-doped $\mathrm{ZnO}$ nanopowders, they are smaller and quasi spherical. Lanthanum doping thus changes the morphology of the
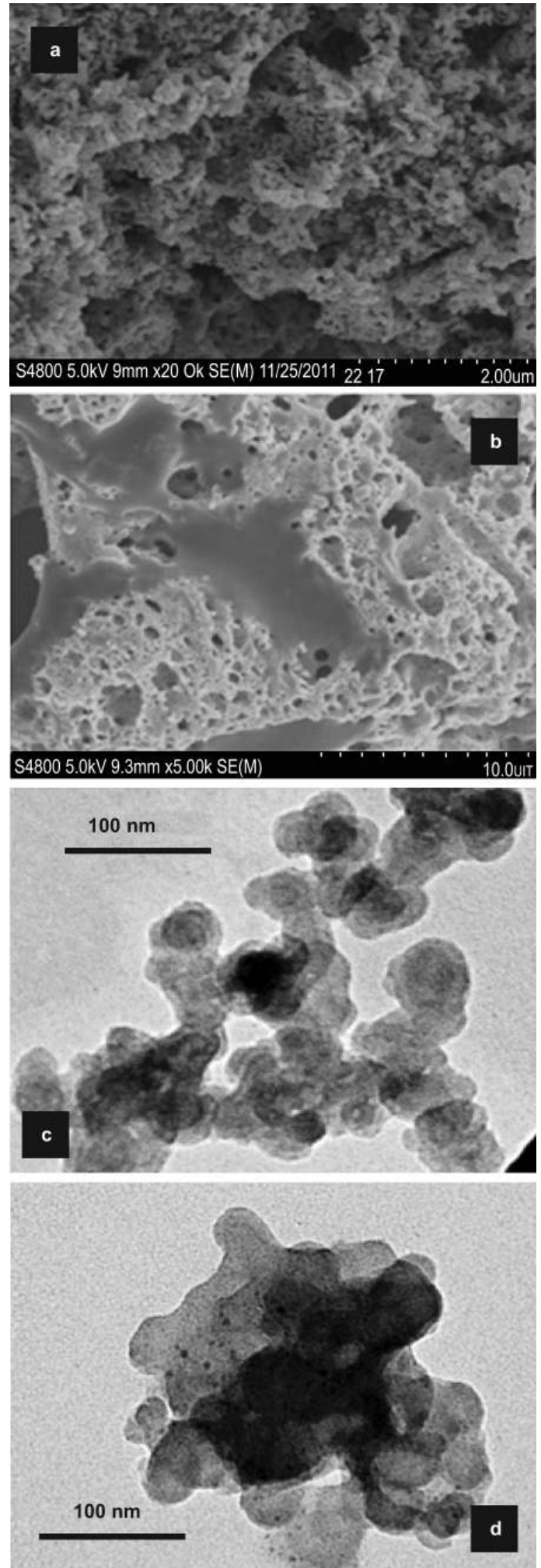

Fig. 2. (a-d) SEM micrograph of (a) pure $\mathrm{ZnO}$ and (b) 2.0 at $\%$ La-doped $\mathrm{ZnO}$ samples; TEM images of (c) pure $\mathrm{ZnO}$ and (d) 2.0 at $\% \mathrm{La}-$ doped $\mathrm{ZnO}$ sample. 
final product. TEM investigations of all of the samples revealed that the crystallites are of nanometer size. The diameter of $\mathrm{ZnO}$ and 2.0 at \% La-doped $\mathrm{ZnO}$ were found to be about 33 and $24 \mathrm{~nm}$, respectively agreeing with the XRD results. The chemical compositional analysis is important for monitoring the concentration of the dopant. Figure 3 shows the EDX spectra of undoped $\mathrm{ZnO}$ and La-doped $\mathrm{ZnO}$ nanoparticles. The EDX spectrum of the La-doped $\mathrm{ZnO}$ displays a clear lanthanum line at $4.65 \mathrm{keV}$ showing La doping. No traces of other elements were found in the spectra which confirm the purity of the samples. Also Table 2 shows the atomic percentage of $\mathrm{Zn}, \mathrm{La}$ and $\mathrm{O}$ for undoped and La-doped $\mathrm{ZnO}$ samples. Here the actual concentration of $\mathrm{La}$ is found to be 1.76 at $\%$ for 2.0 at $\%$ La-doped $\mathrm{ZnO}$ sample.

XPS analysis. The nature and the co-ordination of the elements present in the La-doped $\mathrm{ZnO}$ were investigated by X-ray photoelectron spectroscopy (XPS). The La 3d spectrum of 2.0 at\% La-doped $\mathrm{ZnO}$ is shown in Fig. 4.

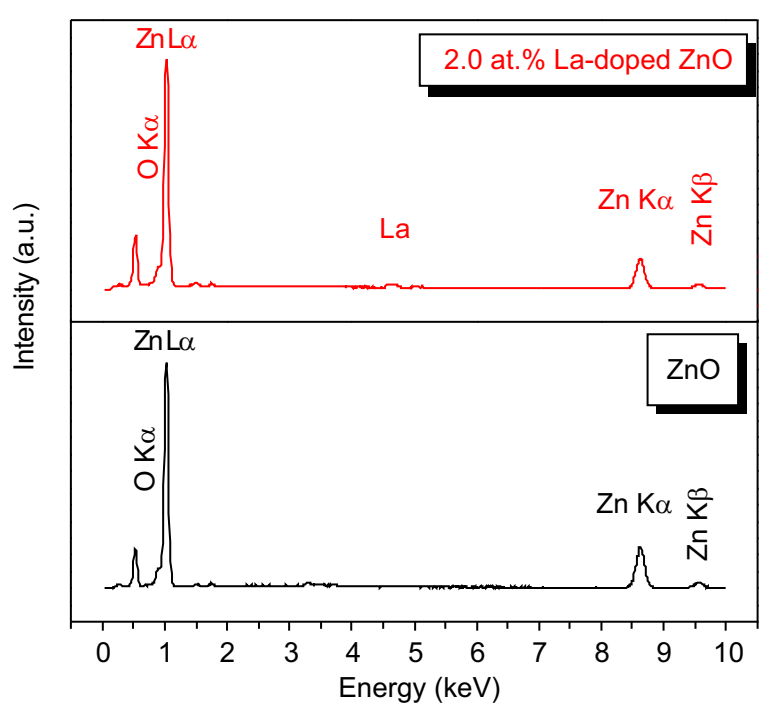

Fig. 3. EDX pattern of $\mathrm{ZnO}$ and 2.0 at $\%$ La-doped $\mathrm{ZnO}$ sample.

Table 2. Chemical composition (atomic \% of $\mathrm{ZnO}$ and La-doped $\mathrm{ZnO}$ sample.

\begin{tabular}{lllll}
\hline \hline Element & Zn (at\%) & O (at\%) & La (at\%) & $\begin{array}{l}\text { Total } \\
\text { (at\%) }\end{array}$ \\
\hline $\mathrm{ZnO}$ & 50.68 & 49.32 & - & 100 \\
2.0 at\% & 48.73 & 49.51 & 1.76 & 100 \\
La-doped & & & & \\
$\mathrm{ZnO}$ & & & & \\
\hline \hline
\end{tabular}

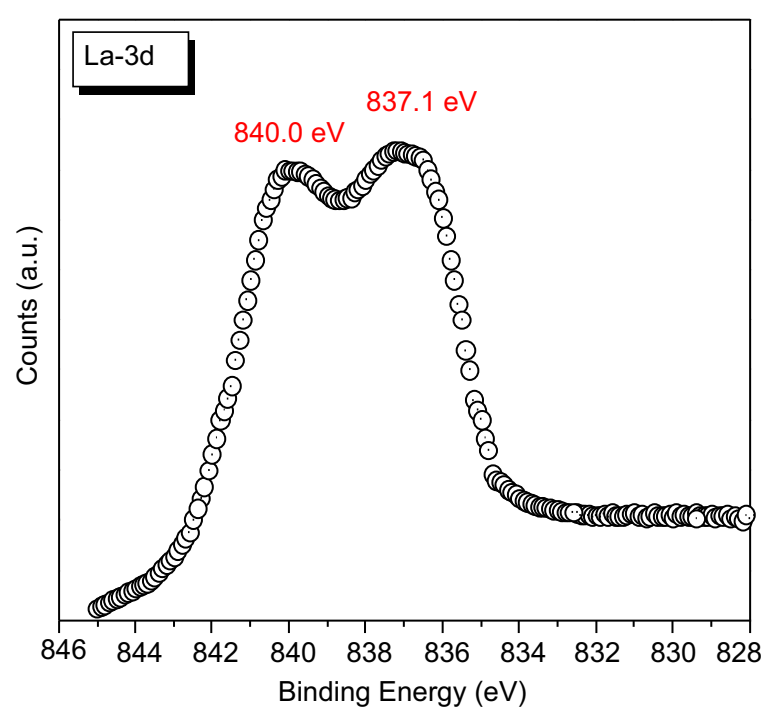

Fig. 4.XPS high resolution spectra of La-3d region for 2 at $\% \mathrm{La}-\mathrm{ZnO}$ sample.

The spectrum exhibits two components with the binding energy values of $837.1 \mathrm{eV}$ and $840.0 \mathrm{eV}$. The highest energy contribution is assigned to the bonding between lanthanum and zinc while the lowest energy contribution is attributed to the bonding in the lanthanum oxide clusters (Anandan et al., 2007). These results demonstrated that the bonding between the lanthanum and zinc has occurred and the interaction between the lanthanum oxide clusters and the $\mathrm{ZnO}$ surface are strongly developed.

UV-visible spectra. Optical properties of $\mathrm{ZnO}$ and Ladoped $\mathrm{ZnO}$ photocatalysts with different La-content were measured by diffuse reflectance spectroscopy (DRS) at room temperature. The absorbance spectra of different samples are shown in Fig. 5. The band edge for the $\mathrm{ZnO}$ sample was appeared at about $387 \mathrm{~nm}$ while the band edges of the La-doped $\mathrm{ZnO}$ samples was shifted to shorter wavelength regions with higher absorption intensity after La-doping. The blue shift in wavelength is attributed to gradual increase in band gap of $\mathrm{ZnO}$ on La-doping. The absorbance coefficient $(\alpha)$ was calculated from the raw absorbance data to obtain the optical band gap (Eg). The band gap values were thus determined by the extrapolation of the linear portion of the $(\alpha h v)^{2}$ curve versus the photon energy hv and are shown in Table 3. With increasing the La-content from 0.0 at $\%$ to 8.0 at $\%$, the band gap energies increased in the range of 3.24-3.27 eV as shown in Fig. 6. The following explanation may be given; the band gap of $\mathrm{ZnO}$ is about $3.37 \mathrm{eV}$ whereas that of $\mathrm{La}_{2} \mathrm{O}_{3}$ is about 


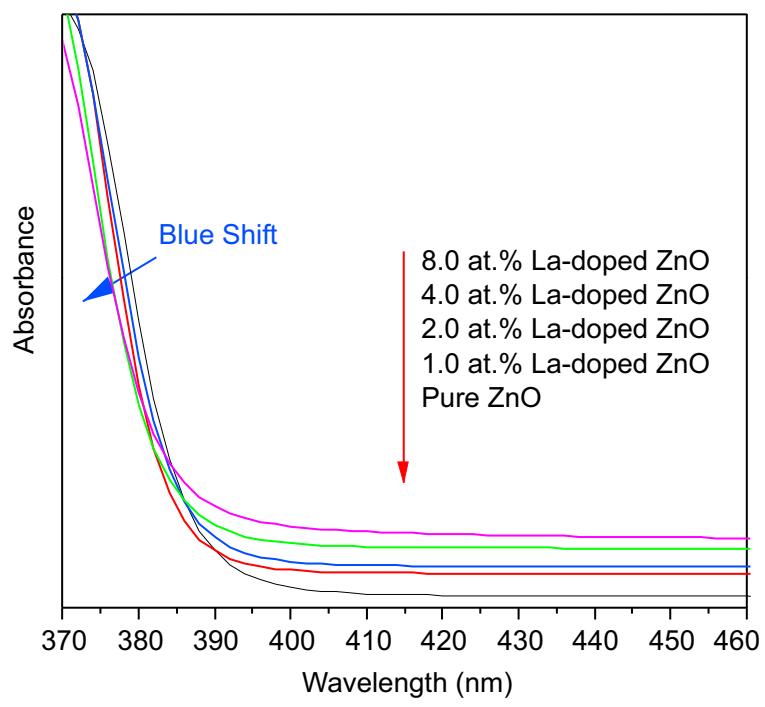

Fig. 5. Absorption spectra for pure $\mathrm{ZnO}$ and $\mathrm{La}-$ doped $\mathrm{ZnO}$ sample.

Table 3. Band gap energy, BET surface area of $\mathrm{ZnO}$ and La-doped $\mathrm{ZnO}$ samples and apparent kinetic values for the degradation MO model dye under sunlight irradiation

\begin{tabular}{lllll}
\hline \hline Photocatalyst & $\begin{array}{l}\text { Band } \\
\text { gap } \\
(\mathrm{eV})\end{array}$ & $\begin{array}{l}\text { BET } \\
\text { surface } \\
\text { area } \\
\left(\mathrm{m}^{2} / \mathrm{g}\right)\end{array}$ & \multicolumn{2}{l}{ For sunlight irradiation } \\
\cline { 5 - 5 } $\mathrm{r}_{0}(\mathrm{mg} / \mathrm{L} / \mathrm{min})$ & $\mathrm{t}_{1 / 2}(\mathrm{~min})$ \\
$\mathrm{ZnO}$ & 3.24 & 33.4 & 0.038 & 217 \\
1.0 at.\% & 3.25 & 37.3 & 0.162 & 86 \\
La-doped & & & & \\
$\begin{array}{l}\mathrm{ZnO} \\
2.0 \text { at.\% }\end{array}$ & 3.25 & 39.5 & 0.132 & 104 \\
La-doped & & & & 130 \\
$\begin{array}{l}\mathrm{ZnO} \\
4.0 \text { at.\% }\end{array}$ & 3.26 & 42.3 & 0.106 & \\
La-doped & & & & 149 \\
$\begin{array}{l}\text { ZnO } \\
8.0 \text { at.\% }\end{array}$ & 3.27 & 45.1 & 0.092 & \\
La-doped & & & & \\
ZnO & & & & \\
\hline \hline
\end{tabular}

$5.5 \mathrm{eV}$ (Jia et al., 2009), which is much higher than that of pure $\mathrm{ZnO}$. An additional energy level could be formed above the conduction band of $\mathrm{ZnO}$ due to the La-doping. Furthermore, this could be attributed to the quantum size effect as well as the strong interaction between the surface oxides of $\mathrm{Zn}$ and $\mathrm{La}$. These observations strongly suggest that the La doping significantly affects the particle size and hence the absorbance properties. Moreover, these results are in good agreement with the conclusion derived from the XRD results and a similar result has also been reported in La-doped $\mathrm{TiO}_{2}$ by

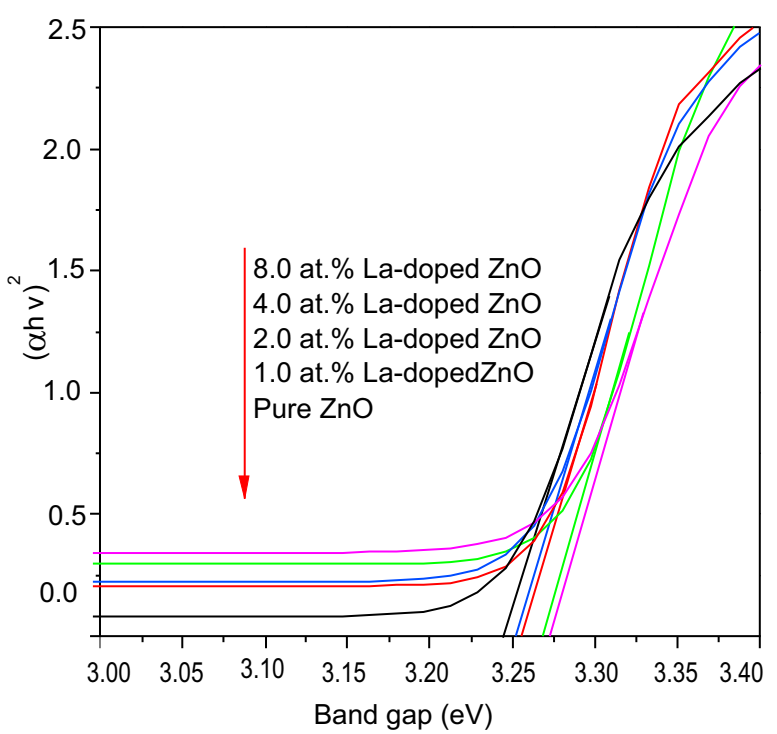

Fig. 6. Band gap energies of $\mathrm{ZnO}$ and La-doped $\mathrm{ZnO}$ sample.

Liqiang et al.(2004) and La-doped $\mathrm{ZnO}$ by Anandan et al. (2007).

Photoluminescence. Photoluminescence (PL) is a powerful tool to investigate optical properties of wide band gap semiconductors. A comparison of PL emission spectra intensity of prepared samples excited with 325 $\mathrm{nm}$ wavelengths ranging up to $600 \mathrm{~nm}$ is shown in Fig. 7. PL emission intensity decreased with Laconcentration i.e. pure $\mathrm{ZnO}$ has highest emission

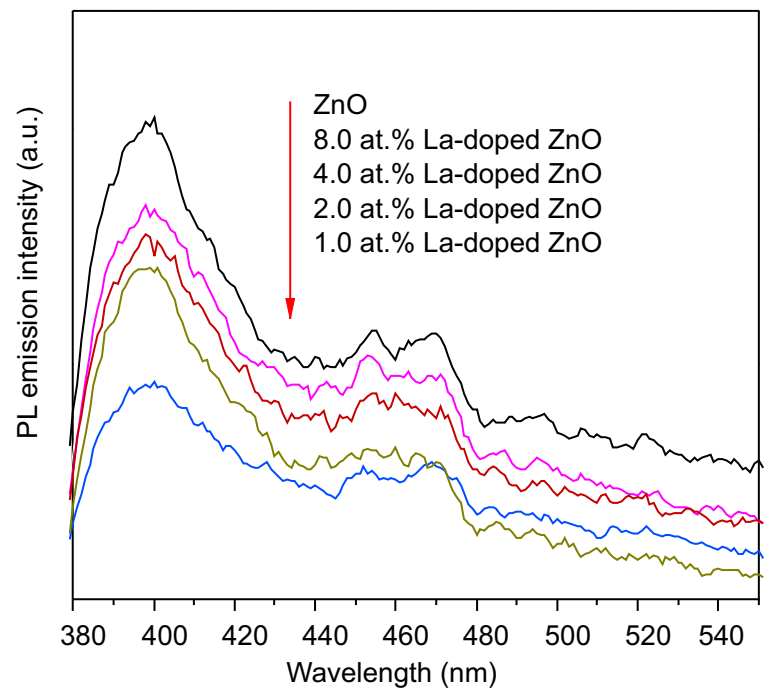

Fig. 7. $\mathrm{PL}$ emission spectra for pure $\mathrm{ZnO}$ and Ladoped $\mathrm{ZnO}$ nanoparticles. 
intensity, which can be attributed to several defects such as oxygen and zinc vacancies or oxygen and zinc interstitials (Ismail et al., 2001). However, the addition of La ions tends to stop the reduction in the band gap resulting in lower PL emission intensity first and then increasing with increasing dopant La-content.

Photocatalytic activity. Pristine $\mathrm{ZnO}$ and doped $\mathrm{ZnO}$ are well known catalysts used in photocatalytic degradation of pollutants. Photocatalytic activities of the $\mathrm{ZnO}$ and La-doped $\mathrm{ZnO}$ samples were determined through a series of experiments carried out for degradation of methyl orange (MO) in aqueous suspension under natural sunlight irradiation. A blank experiment study of MO degradation without catalyst loading under the same condition was also observed. The results indicate that the mere photolysis can be ignored as the corresponding degradation is about $0.3 \%$ after irradiations for $2 \mathrm{~h}$. Figure 8 shows a comparison of photocatalytic performances of pure $\mathrm{ZnO}$ and Ladoped $\mathrm{ZnO}$ nanoparticles. About $9 \%$ of the $\mathrm{MO}$ was adsorbed for $\mathrm{ZnO}$ sample upon stirring for $30 \mathrm{~min}$ in the dark and increased for La-doped $\mathrm{ZnO}$ in comparison to $\mathrm{ZnO}$ nanopowders. The pronounced adsorption is due to increase in specific surface area, increase in porosity and defects creation within band gap by

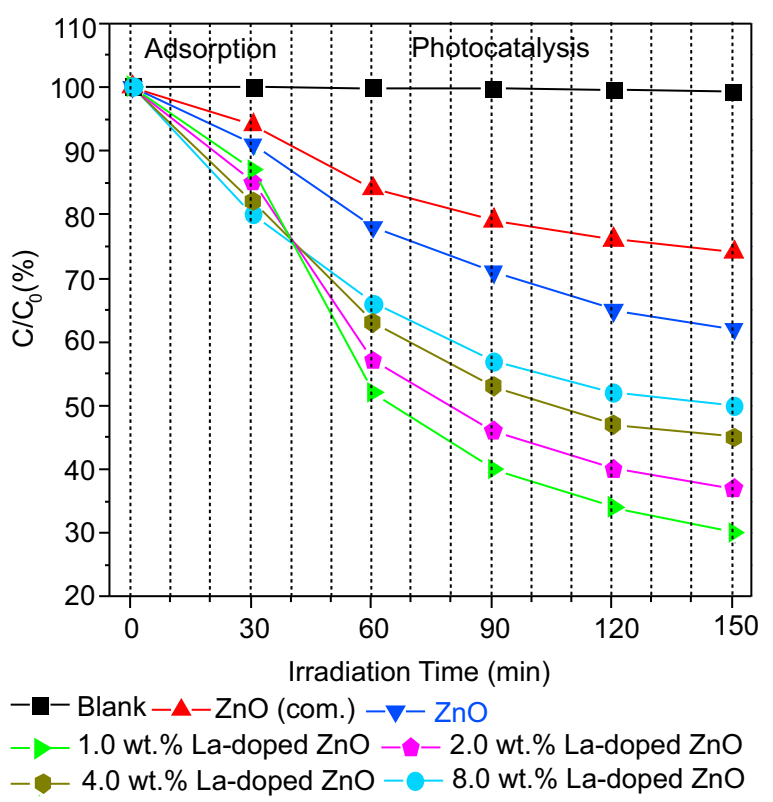

Fig. 8. Photocatalytic activity of pure $\mathrm{ZnO}$, Commercial $\mathrm{ZnO}$ and La-doped $\mathrm{ZnO}$ nanopowders for MO degradation under sunlight irradiation. lanthanum doping. Photocatalytic degradation of $\mathrm{MO}$ follows pseudo first-order reaction kinetics for low dye concentrations

$$
\ln \left(\mathrm{C}_{0} / \mathrm{C}\right)=\mathrm{k}_{\mathrm{appt}}
$$

where:

$\mathrm{k}_{\mathrm{app}}=$ the apparent constant, used as the basic kinetic parameter for different photocatalysts; $\mathrm{C}_{0}=$ the initial concentration of $\mathrm{MO}$ in aqueous solution and $\mathrm{C}=$ the residual concentration of $\mathrm{MO}$ at time $\mathrm{t}$.

The initial degradation rate $\left(\mathrm{r}_{0}=\mathrm{k}_{\mathrm{app}} \mathrm{C}_{0}\right)$ of $20 \mathrm{mg} / \mathrm{L} \mathrm{MO}$ with different photocatalysts was studied and the results are presented in Table 3. The photodegradation rate of MO follows the ascending order; 1.0 at $\%$ La-doped $\mathrm{ZnO}>2.0$ at $\%$ La-doped $\mathrm{ZnO}>4.0$ at $\%$ La-doped $\mathrm{ZnO}$ $>8.0$ at $\%$ La-doped $\mathrm{ZnO}>\mathrm{ZnO}>$ commercial $\mathrm{ZnO}$. The degradation rate under sunlight for $1.0 \mathrm{at} \% \mathrm{La}-$ doped $\mathrm{ZnO}$ photocatalyst was found superior to other La-doped $\mathrm{ZnO}$ and $\mathrm{ZnO}$ samples. The specific surface areas were seen to increase gradually with the increasing lanthanum content (Table 3) enhancing the adsorption performance. The photocatalytic efficiency of La-doped $\mathrm{ZnO}$ mainly originates from the formation of $\mathrm{La}-\mathrm{O}-\mathrm{Zn}$ bonds on $\mathrm{ZnO}$ surface. Photocatalytic degradation rate of MO is observed to be lower under La-doped $\mathrm{ZnO}$. Table 3 shows that the degradation rate of MO enhanced with La-content up to 1.0 at\% La-content and then decreased with La-loading leading to the conclusion that 1.0 at $\%$ doping concentration is the optimum loading to $\mathrm{ZnO}$ that is more efficient in separating photoinduced electron-hole pairs which in turn increases photoactivity of $\mathrm{ZnO}$. The high photocatalytic activity at $1.0 \mathrm{at} \% \mathrm{La}-$ doped $\mathrm{ZnO}$ can be explained as follows: lanthanum ions in $\mathrm{ZnO}$ can result in the formation of a space charge layer on the surface of $\mathrm{ZnO}$ which acts as a barrier for recombination of photoinduced electron-hole pairs resulting in an increase in the photocatalytic activity. This increase was observed up to $1.0 \mathrm{at} \% \mathrm{La}$-doping in the present study. The decrease in photocatalytic activity of $\mathrm{ZnO}$ beyond 1.0 at\% La-doping is justified as: The incorporation of lanthanum beyond $1.0 \mathrm{at} \%$ is supposed to likely result in the formation of more $\mathrm{La}-\mathrm{O}-\mathrm{Zn}$ bond on $\mathrm{ZnO}$ surface due to which surface charge region is negatively affected causing a decrease in its efficiency to separate the photoinduced electron-hole pairs and instead of acting as traps sites for photoinduced electronhole pairs, it acts as recombination centre (Jia et al., 2009). This results in decrease of photocatalytic activity of $\mathrm{ZnO}$. 
A simple mechanism to understand the enhancement of photocatalytic activity of La-doped $\mathrm{ZnO}$ photocatalysts is the loading of lanthanum metals on the $\mathrm{ZnO}$ surface, which can accelerate the transport of photogenerated electrons to the outer systems. The transfer of electrons to the deposited metal causes these to become negatively charged (Behnajady et al., 2009). In the photocatalytic systems, lanthanum deposited on the $\mathrm{ZnO}$ surface increased the photocatalytic activity by accelerating the transfer of electrons to dissolved oxygen molecules. Superoxide anion radical was prepared as a result of oxygen reduction by transfer of trapped electrons from lanthanum metal to oxygen. Consequently, the recombination of the photo-generated carriers were effectively suppressed leading to an increase in the photo-oxidation efficiency. The photocatalyst 1.0 at $\%$ La-doped $\mathrm{ZnO}$ exhibited superior catalytic performance, but further increase in the concentration of lanthanum would decrease photocatalytic activity because too much doping of lanthanum is likely to serve as recombination centre than as trap sites for the charge transfer at the interface. The total organic carbon (TOC) content was measured after the degradation of methyl orange dye in the presence of the photocatalysts under sunlight irradiation. After photodegradation the total organic carbon content of MO was observed to decrease with time and the results are presented in Fig. 9. $\mathrm{TOC}_{\mathrm{o}}$ and $\mathrm{TOC}_{\mathrm{t}}$ are the initial

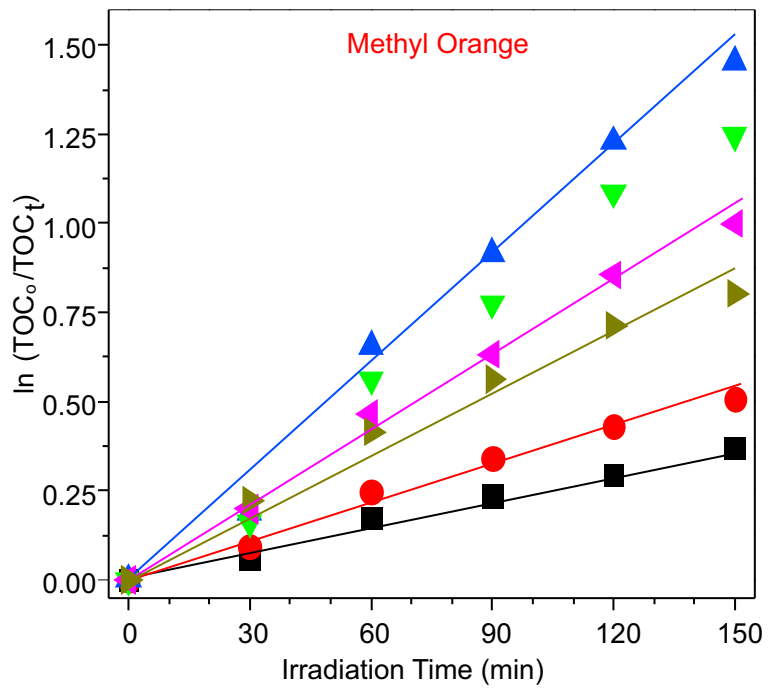

$\mathrm{ZnO}$ (com.) ZnO $\triangle 1.0$ at.\% La-doped ZnO

$\nabla 2.0$ at.\% La-doped $\mathrm{ZnO}<4.0$ at.\% La-doped $\mathrm{ZnO}$

8.0 at.\% La-doped ZnO

Fig. 9. The $\operatorname{In}\left(\mathrm{TOC}_{\mathrm{o}} / \mathrm{TOC}_{\mathrm{t}}\right.$ vs time curves of mineralization of methly orange. concentration and the reaction concentration of MO, respectively. The experimental data are fitted using the pseudo-first-order kinetic equation.

During dye production and textile manufacturing processes an enormous amount of waste water containing dyestuffs with intensive colour and toxicity is introduced into the aquatic system. An effluent of this type has been considered for this photocatalytic degradation study using the same experimental conditions discussed in the experimental section. COD removal efficiencies of the effluent by $\mathrm{ZnO}$, La-doped $\mathrm{ZnO}$ nanopowders

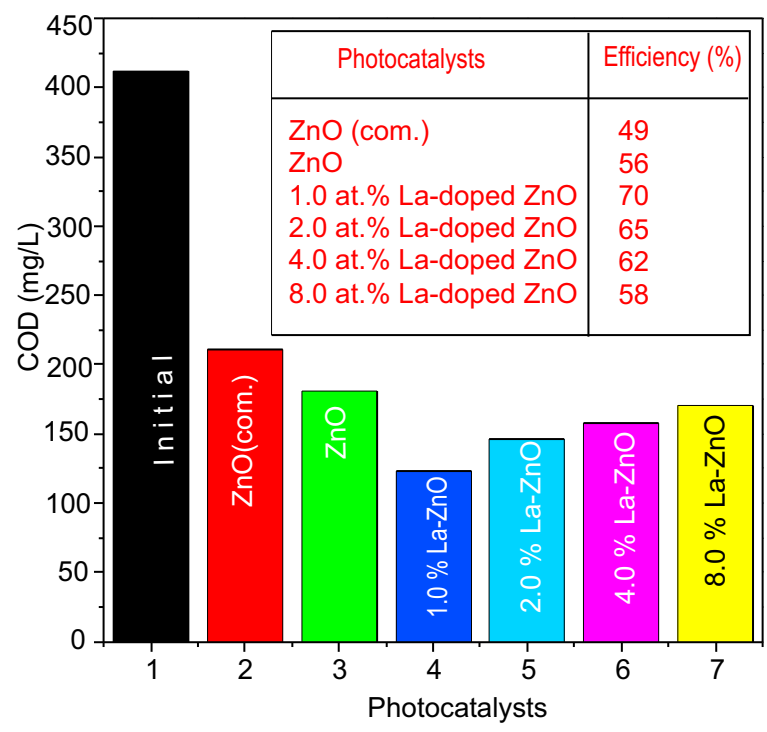

Fig. 10. COD values of the treated effluent and percentage photodegradation efficiency $(\eta)$ for different photocatalysts under sunlight irradiation

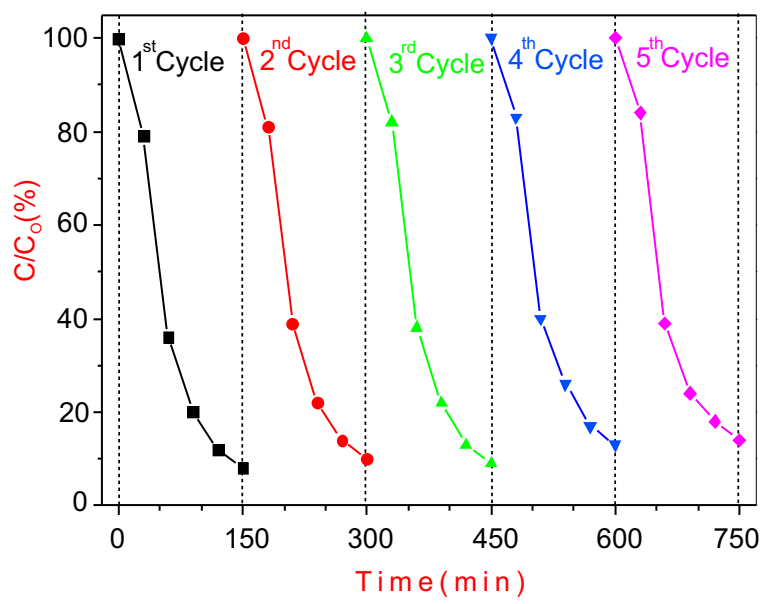

Fig. 11. Photo-stability of 1.0 at $\%$ La-doped $\mathrm{ZnO}$ sample. 
photocatalysts under the sunlight irradiation are shown in Fig. 10. COD reduction confirms the destruction of the organic molecules in the effluents along with colour removal. The photo-stability of 1.0 at $\%$ La-doped $\mathrm{ZnO}$ sample as catalyst under sunlight was also studied (Fig. 11). The photocatalytic activity of the sample did not decrease significantly after five successive cycles of degradation tests, indicating that the photocatalyst was fairly stable under the conditions used in this study.

\section{Conclusion}

Pure $\mathrm{ZnO}$ and La-doped $\mathrm{ZnO}$ nanoparticles were synthesised via fast and facile conventional combustion method and characterised using a variety of characterisation techniques. From XRD patterns all synthesised samples had a hexagonal wurtzite structure showing that La-doping has no structural effect on $\mathrm{ZnO}$. It was found that $\mathrm{La}^{3+}$ is uniformly dispersed on $\mathrm{ZnO}$ nanoparticles in the form of small $\mathrm{La}_{2} \mathrm{O}_{3}$ cluster. The XRD and UV-vis results revealed that the particle size of Ladoped $\mathrm{ZnO}$ is much smaller as compared to that of pure $\mathrm{ZnO}$ and decreases with increasing La loading. Highly porous surface of La-doped $\mathrm{ZnO}$ was observed by SEM, which is critical for enhancing the adsorption and photocatalytic activity. The photocatalytic activity of La-doped $\mathrm{ZnO}$ for the degradation of MO was studied and the results are compared with $\mathrm{ZnO}$ and commercial $\mathrm{ZnO}$. It was observed that the rate of degradation of $\mathrm{MO}$ over La-doped $\mathrm{ZnO}$ increases with increasing $\mathrm{La}$ loading up to $1.0 \mathrm{at} \%$ and then decreases. The TOC results demonstrated that $\mathrm{La}$-doped $\mathrm{ZnO}$ requires shorter irradiation time for the complete mineralization of $\mathrm{MO}$ than pure $\mathrm{ZnO}$. The relative photonic efficiencies and the photocatalytic activity of the 1.0 at $\%$ La-doped $\mathrm{ZnO}$ are much higher as compared to those of pure $\mathrm{ZnO}$ and commercial $\mathrm{ZnO}$. It is concluded that, small particle size, separation of charge carriers, highly porous surface and larger specific surface area of La-doped $\mathrm{ZnO}$ are the major constituents for its enhanced photocatalytic activity in the present study.

\section{Acknowledgement}

Mukhtar Ahmad is thankful to Higher Education Commission (HEC) of Pakistan for providing financial assistance through Indigenous and IRSIP Scholarship Programme and the Zhejiang University of China for providing opportunity to work in its laboratories.

\section{References}

Abed, C., Bouzidi, C., Elhouichet, H., Gelloz, B., Ferid, M. 2015. Mn doping induced high structural quality of sol-gel $\mathrm{ZnO}$ crystals: Application in photo- catalysis. Applied Surface Science, 349: 855-863. Ahmad, M., Ahmed, E., Zafar, F., Khalid, N.R., Niaz, N.A., Hafeez, A., Ikram, M., Khan, M.A., Hong, Z.L. 2015. Enhanced photocatalytic activity of Ce-doped $\mathrm{ZnO}$ nanopowders synthesized by combustion method. Journal of Rare Earths, 33: 255-260.

Ahmad, M., Ahmed, E., Hong, Z.L., Iqbal, Z., Khalid, N.R., Abbas, T., Ahmad, I., Elhissi, A., Ahmed, W. 2013. Structural, optical and photocatalytic properties of hafnium doped zinc oxide nanophotocatalyst. Ceramic International, 39: 8693-8700.

Ahmad, M., Ahmed, E., Hong, Z.L., Khalid, N.R., Zhang, Y., Ullah, M. 2013a. Preparation of highly efficient $\mathrm{Al}$ doped $\mathrm{ZnO}$ photocatalyst by combustion synthesis. Current Applied Physics, 13: 697-704.

Ahmad, M., Iqbal, Z., Hong, Z., Yang, J., Zhang, Y., Khalid, N.R., Ahmed, E. 2013b. Enhanced sunlight photocatalytic performance of hafnium doped $\mathrm{ZnO}$ nanoparticles for methylene blue degradation. Integrated Ferroelectrics, 145: 108-114.

Ahmad, M., Ahmed, E., Hong, Z.L., Khalid, N.R., Elhissi, E., Ahmed, W. 2013c. Graphene-Ag/ZnO nanocomposite as a high performance photocatalyst under visible light irradiation. Journal of Alloys and Compounds, 577: 717-727.

Ahmad, M., Ahmed, E., Khalid, N.R., Jackson, M.J., Ahmed, W. 2012a. Synthesis and characterization of hexagonal shaped nanocrystalline zinc oxide powders. International Journal of Manufacturing Materials and Mechanical Engineering, 2: 61-76.

Ahmad, M., Ahmed, E., Hong, Z.L., Khalid, N.R. 2012b. Effect of fuel to oxidant molar ratio on the photocatalytic activity of $\mathrm{ZnO}$ nanopowders. Ceramic International, 39: 3007-3015.

Anandan, S., Vinu, A., Lovely, K.L.P.S., Gokulakrishnan, N., Srinivasu, P., Mori, T., Murugesan, V., Sivamurugan, V., Ariga, K. 2007. Photocatalytic activity of $\mathrm{ZnO}$ for the degratation of monocrotophos in aqueous suspension Journal of Molecular Catalysis A: Chemical, 266: 149-157.

Behnajady, M.A., Modirshahla, N., Shokri, M., Zeininezhad, A., Zamani, H.A. 2009. Enhancement photocatalytic activity of $\mathrm{ZnO}$ nanoparticles by silver doping with optimization of photo-deposition method parameters. Journal of Environmental Science: Health Part A, 44: 666-672.

Bouderbala, M., Hamzaoui, S., Amrani, B., Reshak, A.H., Adnane, M., Sahraoui, T., Zerdali, M. 2008.Thickness dependence of structural, electrical and optical behaviour of undoped $\mathrm{ZnO}$ thin films. Physica B: Condensed Matter, 403: 3326-3330.

Chen, Y.F., Bagnall, D.M., Koh, H.J., Park, K.T., Hiraga, 
K.J., Zhu, Z.Q., Yao, T.F. 1998. Plasma assisted molecular beam epitaxy of $\mathrm{ZnO}$ on c-plane sapphire-growth and characterization. Journal of Applied Physics, 84: 3912-3918.

Ciciliat, M.A., Silva, M.F., Fernandes, D.M., de Melo, M.A.C., Hechenleitnar, A.A.W., Pineda, E.A.G. 2015. Fe-doped $\mathrm{ZnO}$ nanoparticles: Synthesis by a modified Sol-gel method and characterization. Materials Letters, 159: 84-86.

Culity, B.D., Stock, S.R. 2001. Elements of X-ray Diffraction, $3^{\text {rd }}$ edition., pp. 388 Prantice-Hall Inc., New Jersey, USA.

Dole, B.N., Mote, V.D., Huse, V.R., Purushotham, Y., Lande, M.K., Jadhav, K.M., Shah, S.S. 2011. Structural studies of Mn doped $\mathrm{ZnO}$ nanoparticles. Current Applied Physics, 11: 762-766.

Elangoran, S.V., Chandramohan, V., Sivakumar, N., Senthil, T.S. 2015. Synthesis and characterization of sodium doped $\mathrm{ZnO}$ nanocrystals and its applications to photocatalysis. Superlattices and Microstructures, 85: 901-907

Flickyngerova, S., Shtereva, K., Stenova, V., Hasko, D., Novotny, I., Tvarozek, V., Sutta, P., Vavrinsky, E. 2008. Structural and optical properties of sputtered $\mathrm{ZnO}$ thin films. Applied Surface Science, 254: 3643-3647.

Ghouri, M.I., Ahmad, E., Khalid, N.R., Ahmad, M., Ramzan, M., Shakoor, A., Niaz, N.A. 2014. Gadolinium doped $\mathrm{ZnO}$ nanocrystalline powders and its photocatalytic performance for degradation of methylene blue under sunlight. Journal of Ovonic Research, 10: 89-100.

Hwang, C.C., Wu, T.Y. 2004. Synthesis and characterization of nanocrystalline $\mathrm{ZnO}$ powders by a novel combustion synthesis method. Materials Science and Engineering B, 111: 197-206.

Ismail, B., Abaab, M., Rezig, B. 2001. Structural and electrical properties of $\mathrm{ZnO}$ films prepared by screen printing technique. Thin Solid Films, 383: 92-94.

Jia, T., Wang, W., Long, F., Fu, Z., Wang, H., Zhang, Q. 2009. Fabrication characterization and Photocatalytic ctivity of La-doped $\mathrm{ZnO}$ nanowires. Journal of Alloys and Compounds, 484: 410-415.

Kaneva, N.V., Dimitrov, D.T., Dushkin, C.D. 2011. Effect of nickel doping on the photocatalytic activity of $\mathrm{ZnO}$ thin films under UV and visible light. Applied Surface Science, 257: 8113-8120.

Korake, P.V., Dhabbe, R.S., Kadam, A.N., Gaikwad, Y.B., Garadkar, K.M. 2014. Highly active lanthanum doped $\mathrm{ZnO}$ nanorods for photodegradation of metasystox. Journal of Photochemistry and Photobiology B: Biology, 130: 11-19.
Liqiang, J., Xiaojun, S., Baifu, X., Baiqi, W., Weimin, C., Honggang, F. 2004. The preparation and characterization of La-doped $\mathrm{TiO}_{2}$ nanoparticles and their photocatalytic activity. Journal of Solid State Chemistry, 177: 3375-3382.

Mukherjee, D. 2011. Development of a Novel $\mathrm{TiO}_{2-}$ Polymeric Film Photocatalyst for Water Purification both under UV and Solar Illumination. Ph.D. Thesis, 143 pp., University of Western Ontario, Canada.

Peng, F., Zhu, H., Wang, H., Yu, H. 2007. Preparation of $\mathrm{Ag}$-sensitized $\mathrm{ZnO}$ and its photocatalytic performance under simulated solar light. Korean Journal of Chemical Engineering, 24: 1022-1026.

Reddy, A.J., Kokila, M.K., Nagabhushana, H., Rao, J.L., Shivakumara, C., Nagabhushana, B.M., Chakradhar, R.P.S. 2011. Combustion synthesis, characterization and Raman studies of $\mathrm{ZnO}$ nanopowders. Spectrochimica Acta Part A, 81: 53-58.

Shinde, V.R., Gujar, T.P., Lokhande, C.D., Mane, R.S., Han, S.H. 2006. Mn doped and undoped $\mathrm{ZnO}$ film: A comparative structrual, optical and electrical properties study. Materials Chemistry and Physics, 96: 326-330.

Suwanboon, S., Amornpitoksuk, P. 2011. Preparation and characterization of nanocrystalline La-doped $\mathrm{ZnO}$ powders through a mechanical milling and their optical properties. Ceramics International, 37: 3515-3521.

Wan, X., Liang, X., Zhang, C., Li, X., Liang, W., Xu, H., Lan, S., Tie, S. 2015. Morphology controlled synthesis of $\mathrm{Cu}$-doped $\mathrm{ZnO}$, tubular $\mathrm{Zn}(\mathrm{Cu}) \mathrm{O}$ and $\mathrm{Ag}$ decorated tubular $\mathrm{Zn}(\mathrm{Cu}) \mathrm{O}$ microcrystals for photocatalysis. Chemical Engineering Journal, 272: 58-68.

Wang, Y., Herron, N. 1991. Nanometre-sized semiconductor cluster: Material synthesis, quantum size effects, and photophysical properties. Journal of Physical Chemistry, 95: 525-532.

Xiao, S., Li, H., Liu, L., Lian, J. 2015. Glucose-assisted generation of assembled mesoporous $\mathrm{ZnO}$ sheets with highly efficient photocatalytic performance. Materials Science in Semiconductor Processing, 39: 680-685.

Zhao, T., Fu, Y., Zhao, Y., Xing, L., Xue, X. 2015. Gadoped $\mathrm{ZnO}$ nanowire nanogenerator as selfpowered/active humidity sensor with high sensitivity and fast response. Journal of Alloys and Compounds, 648: 571-576

Zhou, X., Li, Y., Peng, T., Xie, W., Zhao, X. 2009. Synthesis, characterization and its visible-lightinduced photocatalytic property of carbon doped ZnO. Materials Letters, 63: 1747-1749. 